\title{
Notice of double reporting
}

\section{Helmut Bertalanffy • Oliver Bozinov • Niklaus Krayenbühl}

Published online: 19 February 2009

(C) Springer-Verlag 2009

It has been brought to our attention that there is a redundancy of the following publication in our journal:

- Prakash, Singh G, Singh SM (2007) Cyclophosphamideinduced agenesis of cerebral aqueduct resulting in hydrocephalus in mice. Neurosurg Rev Jul;30(3):24551; discussion 251, Epub 2007 Apr 25

contains substantial data and methods as well as discussion from the following article:

- Prakash, Singh G, Singh SM (2007) Cyclophosphamide induced non-canalization of cerebral aqueduct. Neuroanatomy $8: 1-5$,

without referencing that publication or vice versa.

This last study from Neuroanatomy was submitted in April 2006 and should have been referenced by the same first author when submitting his article to our journal in February 2007. The methods of the two studies performed differ only in the administered concentration of cyclophosphamide, with the same goals, and contain common data, results and text. After re-evaluating the articles, both previous reviewers of Neurosurgical Review have classified them as near copies. After being informed, Kasturba Medical College, Bejai, Mangalore, Karnataka, India, has countermanded the article from Neurosurgical Review.

The editors of Neurosurgical Review were not informed of the previous related submission to Neuroanatomy until after Neurosurg Rev Jul;30(3):245-51 had been submitted, accepted and published. This article will be retracted.

H. Bertalanffy ( $\bowtie$, Editor-in-Chief)

Department of Neurosurgery, University Hospital, 8091 Zurich, Switzerland

e-mail: Helmut.Bertalanffy@usz.ch

O. Bozinov (Assistant to the Editor-in-Chief)

Department of Neurosurgery, University Hospital, 8091 Zurich, Switzerland

e-mail: Oliver.Bozinov@usz.ch

N. Krayenbühl (Assistant to the Editor-in-Chief) Department of Neurosurgery, University Hospital, 8091 Zurich, Switzerland

e-mail: Niklaus.Krayenbuehl@usz.ch 